\title{
Percepção materna sobre o apoio recebido para a amamentação: o olhar na perspectiva da vulnerabilidade programática
}

\section{Mother's perception on breastfeeding support: a programmatic vulnerability perspective}

\author{
Laís Silva Lima ${ }^{1}$, Sarah Nancy Deggau Hegeto Souza²
}

\begin{abstract}
Resumo
A pesquisa buscou compreender os relatos das mães sobre o apoio recebido do serviço de saúde e fatores determinantes na opção pela alimentação de seus filhos nos primeiros seis meses de vida, analisando pontos de vulnerabilidade para o não aleitamento. Estudo descritivo, qualitativo, realizado com mães que tiveram seus filhos entre os anos de 2002 e 2008 e eram moradoras das áreas de abrangência de três Unidades Básicas de Saúde do município de Londrina-PR. Para análise das falas foi utilizado a Análise de Conteúdo de Bardin e como referencial teórico o conceito de vulnerabilidade de Ayres, Paiva e Franca. A partir dos resultados surgiram cinco temas: Sentimentos maternos relacionados à amamentação; A influência da família no processo de aleitamento materno exclusivo; Dificuldades na amamentação; Informações recebidas nos diversos cenários de atenção; Apoio recebido dos profissionais de saúde. É possível identificar a intervenção do profissional tanto positiva quanto negativamente, criando ou deixando de reduzir vulnerabilidades. As barreiras para o sucesso do aleitamento podem estar ao alcance de intervenção profissional se forem criadas alternativas de solução onde este atue com seu conhecimento técnico-científico. Nossas ações devem ser pensadas para que, reduzindo-se as vulnerabilidades, consigamos alcançar maiores índices de aleitamento materno exclusivo.
\end{abstract}

Palavras-chave: Aleitamento materno. Profissional de saúde. Vulnerabilidade em saúde.

\begin{abstract}
This research aimed to understand the speeches of mothers who received support from the health service and to understand the determining factors that oriented their decision about feeding their babies aged six months old or younger. Also, we analyzed the vulnerability points that influenced the decision to not breastfeed. This is a descriptive study with a qualitative approach with mothers who gave birth from 2002 to 2008 and received health attention from three Basic Health Centers, located in different areas in Londrina - PR. Bardin's content analysis was used to analyze the speeches, and Ayres, Paiva and Franca' Vulnerability concept was applied as theoretical referral. Five categories emerged from content analysis: Maternal feelings related to breastfeeding; The family's influence in exclusively breastfeeding; Breastfeeding difficulties; Information gathered in different health attention contexts; Support from health professionals. It is possible to identify positive and negative interventions from health professionals, which create vulnerabilities or hinder its reduction. The barriers to successful breastfeeding may be reachable through professional interventions created as an alternate solution, implementing technical and scientific knowledge. Our attitudes must be thought in order to reduce vulnerabilities and therefore reach higher exclusive breastfeeding rates.
\end{abstract}

Keywords: Breastfeeding. Health personnel. Health vulnerability.

1Residente de Enfermagem em Saúde da Criança pela Universidade Estadual de Londrina. E-mail: laislima89@hotmail.com. 2Doutora em Ciências pela EERP/USP, Docente do Departamento de Enfermagem da Universidade Estadual de Londrina. E-mail: sarahuel@sercomtel.com.br. 


\section{Introdução}

O aleitamento materno (AM) é um alimento seguro, que protege as crianças de doenças comuns da infância. Tem destaque como estratégia de fácil acesso e eficácia comprovada na queda da mortalidade em crianças no seu primeiro ano de vida, graças aos inúmeros fatores de proteção do leite materno para as infecções. Ainda para o bebê, há evidências de que o aleitamento materno trás benefícios em longo prazo para um melhor desempenho intelectual e social, diminuição do risco de hipertensão, colesterol alto, diabetes e obesidade, que são problemas de grande impacto para a saúde pública (BRASIL, 2009a).

Por esses e diversos outros fatores, segundo a Organização Mundial de Saúde (OMS), o aleitamento materno deve ser exclusivo até os seis meses de vida e complementado com outros alimentos até os dois anos ou mais (WORLD HEALTH ORGANIZATION, 2012).

Dentre os oito objetivos estabelecidos pela Organização das Nações Unidas para o desenvolvimento do milênio (ODM) no ano 2000, está a redução da mortalidade infantil em dois terços até 2015, a partir das taxas apresentadas em 1990: a cada mil nascidos vivos ocorriam 53,7 mortes em crianças antes dos cinco anos (INSTITUTO DE PESQUISA ECONÔMICA APLICADA, 2004).

No Brasil, foi firmado, em 2003, o Pacto Nacional pela Redução da Mortalidade Materna e Neonatal, entre o governo e gestores do Sistema Único de Saúde (SUS), instituições e profissionais de saúde e instituições não-governamentais. As ações prioritárias contempladas no referido pacto foram incluídas no Plano Nacional de Saúde do Ministério da Saúde, visando promover a atenção integral à saúde da criança e a diminuição da mortalidade infantil, com ênfase na mortalidade neonatal. Entre as linhas de cuidado estabelecidas estava a promoção do aleitamento materno e alimentação saudável (INSTITUTO DE PESQUISA ECONÔMICA APLICADA, 2004).
Londrina tem desenvolvido ações para que aconteça a melhoria dos índices de aleitamento materno, tendo em vista todas as suas contribuições para a saúde da criança. Essas ações vão desde o empenho dos docentes em incluir o aleitamento nos ensino dos cursos de saúde na década de 70 , passando pela criação do banco de leite humano, no Hospital Universitário em 1988, que é referência para o estado do Paraná, até a criação do Comitê de Aleitamento Materno (CALMA) e do Centro de Lactação (CELAC), hoje chamado Clínica de Lactação do Ambulatório do Hospital das Clínicas da Universidade Estadual de Londrina, ambos em 1995. O CALMA congrega diversas instituições, públicas e privadas, de saúde e da comunidade, com a coordenação da Secretaria Municipal de Saúde. Este comitê foi instituído para planejar e coordenar as ações de aleitamento materno do município. $\mathrm{O}$ CELAC presta assistência às nutrizes com dificuldades no processo da amamentação. Londrina conta ainda com três hospitais denominados Hospital Amigo da Criança (HAC), que incluem práticas de incentivo ao aleitamento materno em suas rotinas hospitalares adotando os 10 passos para o sucesso do aleitamento (SOUZA, 2010).

Em 1995, já com a preocupação de fortalecer o AM na atenção primária de saúde, surge a Iniciativa Unidade Básica Amiga da Criança. Podemos dizer que esse foi o berço do que temos hoje: a Rede Amamenta Brasil, pensada e construída por docentes do Curso de Graduação em Enfermagem da Universidade Estadual de Londrina e profissionais do CALMA. Instituída como linha de ação do Ministério da saúde (MS) pela portaria $\mathrm{n}^{0} 2799$, de 18 de novembro de 2008, tem como objetivo a capacitação dos profissionais da atenção primária de saúde para assistência ao processo da amamentação, e é baseada na metodologia crítico-reflexiva e na educação permanente (BRASIL, 2009b).

Em 2008, foi realizada em Londrina uma pesquisa sobre os indicadores de aleitamento materno e obteve-se uma prevalência de AME em menores de 6 meses de 33,8\% (SOUZA et al., 2012) 
. No mesmo ano de 2008, a prevalência nacional foi de 41,0\% e de Curitiba 46,1\% (BRASIL, 2010). Apesar de todas as iniciativas e propostas adotadas pelo município, alguns dos dados estão aquém do esperado, se comparados às recomendações da OMS e do MS.

Diante do exposto podemos nos questionar: será que as mães estão se sentindo suficientemente apoiadas no processo de amamentação pelos profissionais dos serviços de saúde, para que consigam amamentar exclusivamente seus filhos por mais tempo?

Portanto, a presente pesquisa tem como objetivo levantar a percepção das mães quanto ao apoio prestado pelos profissionais do serviço de saúde no processo de amamentação, no município de Londrina. Pretende ainda contribuir com um olhar diferenciado do serviço de saúde para as necessidades e expectativas das autoras do processo de amamentar, trazendo subsídios aos profissionais da área da saúde para uma abordagem especifica, atendendo àquilo que é esperado pelas mães que estão passando pelo período de amamentação.

\section{Caminho Metodológico}

\section{Contexto}

O municipio de Londrina situa-se na região norte do Estado do Paraná/ Brasil, conta com uma população estimada de 510.710 habitantes, sendo 5895 menores de um ano de idade (LONDRINA, 2010).

O sistema de saúde estrutura-se na atenção básica com 52 Unidades Básicas de Saúde (UBS) com suas respectivas equipes de saúde da família. Os campos da pesquisa foram as áreas de abrangência de três Unidades Básicas de Saúde do município de Londrina. A $1^{\text {a }}$ UBS localizada na região sul do município de Londrina abriga uma concentração de aproximadamente 1.956 famílias consideradas em situação de risco, sendo o maior bolsão de pobreza do município de Londrina (LONDRINA, 2010). A $2^{\mathrm{a}}$ UBS, também localizada na região sul do município de Londrina, possui 2.723 famílias cadastradas e 5.586 habitantes. A população com abastecimento de água pela rede pública é de $98,92 \%$ e $99,94 \%$ das casas tem o lixo coletado. O sistema de esgoto está disponível a $80,85 \%$ dos habitantes e $99,36 \%$ dos domicílios recebem energia elétrica. A $3^{\mathrm{a}} \mathrm{UBS}$, localizada na região central de Londrina, tem população estimada de 16.578 , porém a avaliação do Sistema de Informação da Atenção Básica (SIAB) integra apenas 3.977 pessoas, tendo uma população maior de 15 anos 95,14\% alfabetizada.

A escolha dessas regiões deu-se pela possibilidade de se incluir mães de diferentes níveis sociais atendidas em diferentes serviços de saúde, públicos e privados, permitindo assim avaliar a abordagem destes e a percepção dessas mulheres no que se refere ao apoio recebido dos profissionais de saúde.

\section{População de Estudo}

Os critérios de inclusão na pesquisa foram: Mães que tiveram seus filhos, independente de terem amamentado, entre os anos de 2002 e 2008, período decorrido entre a primeira e a segunda pesquisa sobre a prevalência de aleitamento materno no município de Londrina, e ainda, mães que habitavam as áreas de abrangência das UBSs escolhidas e que aceitaram participar na pesquisa.

\section{Procedimentos}

A busca das mães que atendessem aos critérios de inclusão da população de estudo foi realizada no momento que as mesmas acompanhavam seus filhos para a vacinação ou para consulta com o pediatra na UBS. Foram apresentados os objetivos da pesquisa 
e solicitada a participação na mesma. Agendou-se então uma visita para realização da entrevista de acordo com a disponibilidade da colaboradora, em sua residência. Nesse momento, foi apresentado o termo de consentimento livre e esclarecido, com a explicação de seus direitos e forma de participação na pesquisa. Entrando em concordância, após a assinatura do Termo, iniciou-se a entrevista que foi gravada, para obter maior fidedignidade de dados no momento da análise.

A coleta de dados se deu por meio de entrevistas individuais com aplicação de instrumento pré formulado. O número de entrevistadas não foi delimitado a priori, adotando o critério de saturação dos dados coletados, alcançando no total o número de 12 entrevistadas. Esse critério foi aplicado a partir do momento que se tinha abordado moradoras das três áreas de abrangência escolhidas em uma mesma proporção de entrevistas relativas a cada área (quatro entrevistas por área), para que se pudesse ser observada a atuação de diversos serviços de saúde e níveis sociais dentre as entrevistadas.

O projeto foi aprovado pelo Comitê de Ética em Pesquisa da Universidade Estadual de Londrina, conforme o parecer $034 / 10$.

\section{Análise dos Dados}

Os dados qualitativos foram analisados a partir da análise das falas das entrevistadas. As entrevistas foram gravadas e transcritas e a partir daí analisadas. A análise teve o objetivo de apreender o que foi manifestado nas falas das mães em relação ao apoio encontrado para a amamentação.

Utilizou-se o método de análise temática proposto por Bardin (2008): exploração textual, através da leitura e significação, leitura flutuante, delineamento dos temas, análise temática, focalizando as representações, expectativas e argumentos utilizados. Nesta fase, foram demarcados os temas e subtemas.
As falas foram identificadas com a letra $E$ (entrevista), seguida por um número determinado conforme a área de entrevista.

A última etapa de análise consistiu na fase interpretativa, na qual, buscou-se tecer relações críticas entre as idéias explícitas e implícitas no texto e o contexto científico, expresso pelos diferentes atores. Foi utilizado como referencial o conceito de vulnerabilidade, proposto por Ayres, Paiva e Franca Junior (2011), para discussão dos resultados.

\section{A Vulnerabilidade na Amamentação}

O conceito de vulnerabilidade em saúde considera a chance de exposição das pessoas ao adoecimento como a resultante de um conjunto de aspectos não apenas individuais, mas também coletivos e contextuais, que estão implicados com a maior suscetibilidade ao adoecimento e, concomitantemente, com a maior ou menor disponibilidade de recursos de proteção (AYRES; PAIVA; FRANCA JUNIOR, 2011).

As pessoas enfrentam diferentes situações de vulnerabilidade e estas situações podem ser particularizadas pelo reconhecimento de três componentes interligados: o individual, o social e o programático ou institucional (MEYER et al., 2006).

Adotou-se o conceito de vulnerabilidade programática descrito por Ayres, Paiva e França Junior (2011), que envolve os componentes individual e social. Neste eixo da vulnerabilidade reúnem-se o grau e a qualidade de compromisso, recursos, gerência e monitoramento de programas nacionais, regionais ou locais de prevenção e cuidado, aspectos relevantes para identificar necessidades, recursos sociais existentes e otimizar seu uso.

O referencial da vulnerabilidade pode ser útil para qualquer tema, desde que se queira apreender 
e compreender os aspectos sociais e programáticos implicados na determinação e/ou conseqüências de um agravo à saúde em indivíduos ou grupos populacionais.

Em relação ao aleitamento materno, o fato de não ocorrer a amamentação deixa o bebê propenso à aquisição de doenças e em conseqüência com chances aumentadas para a morte. Porém a decisão da mãe em não amamentar não deve ser relacionada exclusivamente à sua vontade, mas sim analisando todo um contexto que envolve questões culturais e sociais, bem como a consciência que esta apresenta sobre os malefícios implícitos no fato de não amamentar e o poder de transformação que existe em seus potenciais.

É diante destas situações de vulnerabilidade que se dispôs a analisar o que foi exposto pelas mães atendidas no serviço de saúde de Londrina e identificar pontos de intervenção, com o objetivo de reduzir a vulnerabilidade ao não aleitamento, em especial no que diz respeito à vulnerabilidade programática.

\section{Resultados e Discussão}

A partir da análise de dados construíram-se cinco temas pertinentes ao que as mães expressaram como percepção de apoio para a amamentação. São eles: Sentimentos maternos relacionados à amamentação; A influência da família no processo de aleitamento materno exclusivo; Dificuldades na amamentação; Informações recebidas nos diversos cenários de atenção; Apoio recebido dos profissionais de saúde. Tais temas serão discutidos a seguir.

\section{Sentimentos Maternos Relacionados à Amamentação}

Observou-se, nas falas, um paralelo entre o sentimento de prazer durante o ato de amamentar e o bom êxito deste, em que são valorizados o contato, o olhar e os sentimentos que este momento proporciona:
Foi uma delicia amamentar. É um carinho tão grande, é uma coisa tão forte... te deixa feliz, é muito gostoso (E1).

Então eu acho assim, que amamentar, não faz bem só porque o leite materno contém mais nutrientes, porque produz anticorpos para o bebê. Mas ele faz bem por causa do contato do filho com a mãe, eu gostava muito dessa parte, porque daí você cria um vínculo com as crianças que ninguém mais tem (E3).

Mas é uma coisa que passa para a mãe, para o filho... Amor, atenção, dar uma parada pra ele (E10).

A melhor parte é dar mama olhando pra ele assim, ele olha pra você... sente... vê o contato entre mãe filho [...] você não tem que levantar, esquentar leite, dar mamadeira, aquele frio, você ter que levantar (E11).

O significado da amamentação, expresso como forma de relação e interação entre mãe - filho, estabelece-se para além do que diz respeito ao benefício gerado para o recém nato. É um contexto amplo, permeado por sentimentos e necessidades tanto da criança quanto da mãe que o amamenta.

O prazer sentido pelo aleitamento é um forte aliado para o sucesso deste. Muitas mães relatam que as dificuldades vividas são compensadas pelo sentimento que este momento proporciona para o binômio. É importante que se esteja atento para a maneira como cada mulher percebe a amamentação, para que não se cometa o erro de associá-la somente a demonstração de amor da mãe pelo filho. Nesta pesquisa não foi diferente o que se ouviu sobre ambas as opiniões.

Olhar para a nutriz como mulher, mãe, esposa, trabalhadora, cidadã é essencial para que seja implementado um cuidado integral, tendo nesta figura protagonista da amamentação muito além do aspecto biológico que o ato de amamentar estabelece. Com este olhar está se levando em consideração suas emoções e sentimentos.

Nakano (2003, p. S357) nos adverte que:
As sensações corporais e as práticas que se passam no corpo materno são determinadas por representações culturais de maternidade e imprimem maneiras socialmente reconhecidas de perceber e agir frente a situações que se apresentam na amamentação, podendo ser vivenciadas pelas mulheres em consonância ou em conflito com as determinações sociais, deixando emergir seus limites. 
Em contra partida as mães que não mantiveram a amamentação referiram os seguintes sentimentos:

Estranho! Ah, eu estranhava... estranho [...] Mas que diz que é gostoso, é gostoso, eu não acho não (E5).

Eu não gostava muito não... Sei lá, eu me sentia esquisita amamentando. [...] Ai depois ela não quis mais. Eu achei até que foi bom porque daí depois que cresce quer ficar mamando até uns seis anos, e eu acho muito feio (E9).

Nossas orientações devem ser embasadas no individualismo de cada mulher, considerando também seus momentos de dificuldades e em muitos casos se apoiando nas vantagens que a amamentação apresenta para ela e para o bebê e não romantizando $\mathrm{o}$ ato de amamentar e relacionando-o com o amor materno.

As mesmas mães que manifestaram percepções negativas em relação ao sentimento de amamentar referem-se com pudor à exposição que a amamentação implica:

Acho que pelo fato de estar trabalhando... De chegar alguém e eu ficar meio constrangida [...] (E5).

Porque daí agente ta no posto assim, tem que tirar pra da mama, eu não... pra mim eu acho que não dá não... porque vai que... É esquisito, grandão pedindo mama, ah não (E9).

A erotização do seio na cultura ocidental é recente, pois este era visto apenas como fonte de alimentação. A sociedade, a cultura e o meio determinam a maneira como o seio é ligado ou não à sexualidade e a erotização do corpo feminino. A mulher deve sentir-se livre e apoiada em sua decisão sobre como utilizar seu corpo, sendo livre do julgamento por sua possível decisão de não amamentação (MONTEIRO; GOMES; NAKANO, 2006).

Respeitar os sentimentos maternos e a maneira como ela reconhece a amamentação é necessário para que se tenha uma abordagem em que o profissional de saúde possa apoiar a mãe a partir de suas concepções e seus valores, criando caminhos que favoreçam o processo da amamentação. Deste modo estamos contribuindo para a redução da vulnerabilidade criada pelo serviço, quando se utilizam de abordagens generalizadas para todas as lactantes, sem avaliação de suas concepções e do contexto no qual ela está inserida.

\section{A Influência da Família no Processo de Ame}

$\mathrm{O}$ ato de amamentar requer uma tomada de decisão por parte da nutriz, que envolve os seus valores, experiências pregressas, ou conhecimentos passados por gerações anteriores. Deste modo a mulher que se depara com esta necessidade de escolha está cercada por pessoas que muitas vezes já viveram o aleitamento ou acompanharam muito de perto, trazendo consigo conhecimentos que lhes são transmitidos neste momento.

As mães, em especial as primíparas, sentem a necessidade deste apoio e colocam, principalmente na figura da avó, a confiança para os cuidados despendidos ao recém-nato.

Nas falas a seguir as mães citam a avó como participante do processo de alimentação da criança, influindo na persistência para o aleitamento e também na introdução de outros alimentos antes dos seis meses de idade:

\footnotetext{
Minha mãe também me apoiou muito para que eu amamentasse [...] Aprendi muita coisa da minha mãe sobre isso (E1).

Eu morava perto da minha mãe, a gente já começou a dar papinha, suquinho, ai minha mãe fazia mingauzinho (E11).
}

A opinião da mulher-avó é indiscutivelmente válida quando levamos em consideração toda sua vivência e experiência adquirida ao longo dos anos, sendo ela considerada herdeira de um processo cumulativo de conhecimentos (TEIXEIRA; NITSCHKE, 2008). É importante saber que há esse processo de construção dos saberes, para que se possa intervir eficientemente, lembrando sempre que esses indivíduos têm suas histórias, que se formam de maneiras peculiares e únicas a cada um.

Sabe-se que muitas vezes os conceitos criados por cada indivíduo trazem mitos e verdades que são tidas como absolutas e rigorosamente seguidas. É comum se ouvir: "O leite é fraco, não vai sustentar 
a criança" ou então "dá um chazinho para acalmálo", “essa criança precisa de água”. Estas são realidades muito próximas, que fazem com que o aleitamento exclusivo seja rompido, muitas vezes por insegurança de "mães de primeira viagem", ao ouvirem alguém próximo que tem certa experiência e desacreditarem em sua capacidade de nutrir seus bebês.

Teixeira e Nitschke (2008) colocam que estas orientações, tais como a introdução de líquido ou leite fraco, surgem de uma época em que não se valorizava a prática do aleitamento materno e seus benefícios.

O serviço de saúde deve trabalhar com tais benefícios e desvendar os mitos que podem existir em cada seio familiar, trabalhando desde o prénatal juntamente com o pai, bem como incluindo os acompanhantes no cuidado já na maternidade e realizando visitas puerperais para avaliação do contexto em que se insere cada nutriz, dirigindo suas orientações também aos cuidadores.

Dentre as principais causas de introdução de outros alimentos antes do sexto mês de vida, relatado pelas mães, está a influência de terceiros por meio de orientações, conselhos, pressão exercida sobre a lactante (MARQUES et al., 2010).

Olhando para a figura paterna nota-se nos relatos seguintes que ao mesmo tempo em que esta representa apoio frente às dificuldades vivenciadas pela mãe, pode também influenciar no desmame ou ainda ter seu lugar na família preterido em benefício do filho:

Ele acaba tendo que ir pra sua cama e o seu marido acaba tendo que sair da cama (E1).

Eu tive o apoio do meu marido [...] Porque daí o pai mesmo já começou a empurrar, sabe? (E7).

Muitas vezes colocado como momento de interação entre mãe e filho, o aleitamento, quando não bem trabalhado em família, acaba por excluir o pai, podendo prejudicar a relação entre o casal. Como já citado neste estudo, a importância dos familiares, em especial do companheiro, é bastante relevante no enfrentamento de dificuldades que a amamentação apresenta e deve ser trabalhada de forma a aproveitar esse benefício.

Não se pode permitir que o pai seja colocado em segundo plano nesta relação que o ato de amamentar faz acontecer. Faz-se necessária a inclusão do companheiro desde o inicio da gestação, incluindo-o, sobre tudo, no processo de amamentação.

Susin e Giugliani (2008) trazem como resultado de sua pesquisa que $93,3 \%$ das mães abordadas gostariam de receber o apoio de seus maridos/ companheiros e que $99,2 \%$ dos pais gostariam de dar assistência, embora não sabendo como fazê-la.

A inclusão destes pais no cuidado e apoio a amamentação precisa ser mediada pelo profissional de saúde, incluindo este indivíduo em suas orientações e intervenções e discutindo com o casal as maneiras como este pai pode interferir no processo, de forma positiva. O processo de trabalho dos serviços de saúde com agendamento de consultas em horários pouco flexíveis pode criar a impossibilidade da participação do pai neste momento.

As mães também fizeram menção ao "desejo" da criança sobre outros alimentos consumidos pela família, determinando a interrupção da amamentação exclusiva:

Ela ficava olhando assim, com os olhinhos, querendo, a gente dava (E9).

Ah, via todo mundo comer, ela queria comer... (E11).

O lactente aprende sobre a sensação de fome e saciedade e desenvolve, ao longo dos meses, a percepção para os sabores e as suas preferências. Portanto não podemos dizer que ao ver determinado alimento a criança sente vontade de comê-lo, mas sim é atraída pela cor, aspecto, uma vez que encontrase na fase de exploração. Para nós, profissionais de saúde, isso pode parecer trivial, mas é importante que esta orientação seja dada à mãe e à sua família, em especial em consultas de puericultura, para que esta idéia seja desvelada. 
Este tema remete à importância da família para a decisão de como a mulher irá suprir as necessidades alimentares de seu filho. As mães colocam a família como importante fonte de apoio, então cabe aos profissionais incluí-la em suas orientações com abordagens adequadas, reconhecendo seus saberes e criando juntamente com a mãe e família as possibilidades para a amamentação daquela criança diante do contexto.

Negar isso é criar vulnerabilidades para essas mulheres, pois se conhece o papel da família neste processo, e sendo omissos, colabora-se para a prática errônea do aleitamento ou determinando o não aleitamento. Os serviços criam situações de vulnerabilidade para as famílias quando não buscam a inclusão das mesmas na assistência à nutriz, desconsiderando a influência que podem exercer na decisão da mulher de amamentar.

\section{Dificuldades na Amamentação}

Ouvindo as protagonistas deste processo, pode-se apreender alguns aspectos que devem ser repensados e levados em consideração, no que diz respeito à redução da vulnerabilidade ao não aleitamento em relação às dificuldades apresentadas no aleitamento.

As fissuras mamilares foram referidas como maior dificuldade para prosseguir com a amamentação, considerando-se a frequência e intensidade em que foram colocadas:

Foi bem sofrido amamentar, eu não tinha o bico bem formado, machucou bastante, sangrou bastante (E1)

Mas racha, sai sangue, dói. Muitas mães não querem amamentar por causa disso (E3);

Porque ela não pegava direito, ai doía demais [...] Mas eu colocava e ela só queria pegar o biquinho, o biquinho dói, tinha que pegar a rodela (E9).

E eu não agüentava, não agüentava de tanta dor no meu peito, o meu peito ficava desse tamanho, parecia que eu tinha colocado silicone [...] (E12).

Durante o processo de amamentação surgem dúvidas e dificuldades que muitas vezes não apareciam antes de a mãe encontrar-se frente à prática da amamentação e de todo o impacto que ela gera em sua vida. Este momento é crucial para a tomada de decisão sobre o continuar ou não o aleitamento, visto que com essa vivência fortificam-se os conceitos particulares que cada uma experiência.

Sabe-se que esta condição de vulnerabilidade apresentada pode ser reduzida significativamente por meio de nossa intervenção profilática e curativa. É necessário que se tenha uma orientação efetiva sobre o posicionamento e a pega correta, ordenha manual, desde o pré-natal, passando pelo período de internação hospitalar, até as primeiras puericulturas e consultas puerperais realizadas em domicílio e na Unidade Básica de Saúde.

A responsabilidade de amamentar focada na figura materna aparece como um fardo, em consequência de toda atenção e tempo que muitas vezes é requerido para o aleitamento:

[...] depois eu não agüentei mais, também, ficar tirando, porque aí eu não dormia [...]. Então era aquele ciclo que eu não dormia, eu não descansava nunca, porque enquanto ele tava dormindo eu tava tirando leite (E2).

Aí fui conseguindo, fui cortando, porque dava uma canseira, que não dormia, porque era a noite inteira se deixasse (E5).

Aí eu não tinha tempo pra nada, eu tinha outras coisas para fazer (E9).

Além do espaço social conquistado nas últimas décadaspelas mulheres, estas trazem consigoacultura de responsabilidade sobre os deveres domésticos e cuidados com os filhos. A amamentação ganha, muitas vezes, a face sacerdotal, que implica à nutriz um compromisso indissolúvel, uma obrigação, um fardo. É possível ainda que esta maternidade seja desejada, escolhida pela mulher e vivenciada como momento de prazer (SILVA, 1990).

Mostra sua importância novamente à intervenção do profissional de saúde para planejar juntamente com a mãe e família alternativas que possam possibilitar a essa mãe momentos de descanso, lazer e dedicados também a ela. É necessário que esta mãe seja vista como mulher, e não apenas como única responsável por suprir as necessidades do bebê. 
A dificuldade em manter a amamentação, afetada pela volta para o trabalho foi citada por algumas das mães entrevistadas:

E ela mamou pouco tempo também... Porque eu trabalhava, ai ela ficava junto comigo. Ai às vezes ela tava mamando ai chegava alguma pessoa e você tinha que atender $[\ldots]$ (E5)

Eu trabalhava tanto na época, tanto, tanto, que eu não tinha tempo de quase nada (E8)

Observou-se na pesquisa realizada por Muller e Silva (2009), que também ouviram as mães sobre o apoio recebido para a amamentação, que o principal relato sobre o desmame precoce é o retorno ao trabalho e à falta de apoio que encontram nestes ambientes.

A estratégia utilizada para preparar a criança e a mãe para o momento de separação, dado pela volta ao trabalho, é a introdução da mamadeira e de outros alimentos, pois muitas vezes as mães não encontram nas instituições de trabalho e de atendimento ao lactente local apropriado para a ordenha e refrigeração adequada do leite, além da falta de orientação quanto a estes procedimentos. É nesta vertente que devem se apoiar as ações dos profissionais de saúde, com o intuito de diminuir a vulnerabilidade criada pelos aspectos sociais desta nutriz.

Outro aspecto apontado durante a entrevista como dificuldade, mesmo que indiretamente, foi a barreira para acesso ao serviço de saúde:

Levar pra fazer puericultura assim não... [...] porque daí eu tinha que subir com os dois aquela subida lá do [...] até aqui, ai eu falei 'ah não dá não, ter que ficar atravessando aquela BR (rodovia que separa o bairro onde a entrevistada reside da UBS) (E12).

Embora não seja reconhecido pela mãe que a dificuldade de acesso interfira no processo de amamentação, é certo que a não participação na puericultura aumenta a vulnerabilidade ao não aleitamento materno ou desmame precoce, bem como a outras necessidades no desenvolvimento da criança em seus primeiros anos de vida.

Reduzir a vulnerabilidade diante da situação social de dificuldade de acesso ao serviço é dispor de recursos programáticos, como a visita domiciliar puerperal, que garante um atendimento integral, universal e com equidade, como é proposto pelas diretrizes do SUS. Este momento de visita mostrase enriquecido pelas possibilidades que ele trás de estabelecer o vínculo com o profissional, além da escuta e observação da realidade (LOPES; SAUPE; MASSAROLI, 2008).

O serviço de saúde deve estar atento a todas as dificuldades enfrentadas por estas mães, desde o acesso, dificuldades com a pega, adequação à volta ao trabalho, até necessidades intrínsecas a cada família. Olhar e intervir nas dificuldades a partir das experiências tecidas na vivência destas mães é reduzir a vulnerabilidade individual e social à que estas ficam submetidas, de forma que se promova a amamentação no universo individual que nasce ao redor de cada nutriz.

\section{As Informações Recebidas em Variados Cenários de Atenção}

Como já citado anteriormente o apoio e orientação em relação ao aleitamento deve contemplar todos os cenários de atenção à saúde da mulher e da criança desde o momento em que esta mãe encontra-se gestante até durante as visitas realizadas ao serviço para acompanhamento do crescimento e desenvolvimento da criança.

Nesta pesquisa apreendeu-se algumas das orientações feitas pelos profissionais de saúde à estas mães, observando o seu conteúdo e o momento em que foram realizadas.

Começando pela realidade apresentada nas consultas pré-natais, foram apontados como orientações: o tempo indicado para a amamentação exclusiva, alguns mitos existentes, a alimentação adequada para a mãe, os benefícios do aleitamento para mãe e para a criança, como podemos observar nas falas abaixo: 
[...] deu uma cartilha falando sobre a amamentação, que seria bom amamentar, que era bom tanto pra mim, quanto para criança... Que você tem que tem que ter paciência, calma [...] que umas pessoas têm mais facilidade, outras não [...] Eles falavam que você deve amamentar até o sexto mês, que não precisa dar água, nem chazinho, nada. E que não existe leite fraco, que não tem esse negocio de que o leite é fraco. [...] E a alimentação também, que você precisa tomar cuidado com certos tipos de alimentos: bebida alcoólica, comida muito forte, porque tudo que você come passa no leite né? [...] (E4).

Ai os médicos que me orientaram a amamentar até seis meses, Porque antigamente era até 6 meses (E5).

$\mathrm{Ah}$, que criança amamentada, que faz muito bem à saúde, da criança... E também que evita o negócio de doença na mama, câncer de mama... (E6).

$\mathrm{Ah}$, eles falavam assim que tinha que amamentar, que tinha bastante coisa no leite, bastante vitamina, que tinha tudo (E9).

No pré-natal simplesmente eles falaram para mim assim não deixar de colocar ele no peito, ate os seis meses (E12).

Percebeu-se que as orientações provenientes da consulta de pré-natal estão sustentadas na informação de que o leite materno é recomendado até o sexto mês de idade exclusivamente e sua importância para a saúde da mãe e da criança.

Em primeiro lugar é necessário que se avalie a qualidade da comunicação dispensada pelo profissional de saúde, para que se tenha a certeza do entendimento correto de suas orientações. Fica claro nas falas a má compreensão em relação à manutenção do aleitamento até o sexto mês e o que significa fazê-lo exclusivamente, sendo evidenciado quando as mães foram questionadas quanto à duração do aleitamento materno exclusivo de seus filhos:

Ah... até um ano e pouco, ele só começou a tomar leite de vaca com um ano e pouco... (E1).

Até os dois anos, mamadeira ela não mamava, só com dois anos que daí eu comecei a tirar ela do peito que ela começou a mamar mamadeira... (E6).

Aleitamento materno exclusivo significa que a criança não está recebendo nenhum outro tipo de líquido, que não o leite da mãe, ou sólido e não que não está recebendo outro tipo de leite. Esta é a meta para os seis primeiros meses de vida, que não se introduzam outros alimentos, chás ou água, além do leite materno (WORLD HEALTH ORGANIZATION, 2012). Para essas mães, ao serem questionadas sobre o AME, respondiam sobre o AM como único tipo de leite oferecido para a criança, quando já haviam introduzido outros alimentos.

O Ministério da Saúde (BRASIL, 2009a) aponta os aspectos que devem ser abordados em relação ao aleitamento, durante o pré-natal: plano da gestante com relação à alimentação da criança; importância do aleitamento materno; vantagens e desvantagens do uso do leite não humano; importância da amamentação logo após o parto, alojamento conjunto, técnica adequada na prevenção de complicações; possíveis dificuldades e meios de previní-las; comportamento normal do recém nascido; vantagens e desvantagens do uso da chupeta.

A intervenção relacionada ao cuidado com as mamas durante o pré-natal foi referida por uma das mães entrevistadas:

Ah as enfermeiras falavam assim pra tomar sol no peito que é muito bom, daí, depois, que não racha (E11).

A promoção da amamentação no pré-natal tem impacto na prevalência de aleitamento materno, em especial, nas primíparas (BRASIL, 2009a). Em relação ao cuidado com as mamas é preconizado pelo Ministério da Saúde (BRASIL, 2009a) que não se deve orientar no pré-natal a aplicação do próprio leite no mamilo, pois a expressão estimula a ocitocina, o que pode desencadear o trabalho de parto prematuro. Também é reforçado que os exercícios para protrair e fortalecer os mamilos, bem como as conchas para mamilos invertidos não demonstram efetividade e prejudicam a integridade cutânea, não devendo ser indicadas durante esse período. O banho de sol é orientado para a prevenção para que se mantenham os mamilos secos, evitando a maceração cutânea e consequente fissura.

No que diz respeito às orientações e informações recebidas no cenário hospitalar o município de 
Londrina mostrou-se muito bem amparado pelos profissionais de saúde nesta fase de atendimento, sendo o local mais referenciado quanto ao apoio e orientações eficazes para o estabelecimento e manutenção com sucesso da amamentação.

Encontrou-se menções de informações sobre a composição do leite, pega correta, cuidados e prevenção de complicações, como se observa nas falas a seguir:

\begin{abstract}
Falou sobre o colostro, tudo, que era importante, me ajudavam a colocar ele no peito [...] Quando eu o ganhei a enfermeira que me ajudou, me ensinar como que fazia (E1).

O modo de pegar, o modo de segurar, o modo de deixar mais encaixadinho no colo, a altura, a forma que o bebê tem que pegar no bico, que é a boquinha de peixe, em toda a aréola (E2).

Eu lembro que o médico que me acompanhou me ensinou a fazer aquelas massagens no bico do peito, pra aumentar o tamanho do bico, usar um creme que deixasse ele mais rígido, engrossasse mais a pele, fortalecesse... (E3).

No hospital também fui muito bem atendida [...] que era bom amamentar, me ensinaram como pegar a criança, para por para amamentar. Porque no começo a criança não sabe, nem ela nem a gente... e que tem que ser nos dois peitos, amamentar... Que se tivesse endurecendo, tem que fazer massagem e tudo... e para fazer o biquinho, como que tem que fazer (E4).
\end{abstract}

Ajudaram, colocava no peito para ver se ele pegava... ai de tanto eu ficar tentando, elas também, ajudando, ele conseguiu pegar (E6).

Eu não sabia arrumar o peito na boca. [...] Ai ela ensinou como colocar o peito na boca dela, para não rachar meu peito. [...] tem que colocar todinha a aréola na boca dele... Ela me ensinava: Se for tirar a boca não puxa, porque machuca o bico, põe o dedinho $\operatorname{assim}(\mathrm{E} 11)$.

Pode-se atribuir o sucesso nas orientações adequadas e a percepção deste apoio no âmbito hospitalar ao fato deste município contar com três instituições que adotaram os 10 passos para o sucesso da amamentação (IHAC), e que tem mostrado seus resultados também no relato das mães que viveram esse apoio.

Segundo a pesquisa nacional de prevalência do aleitamento materno realizada em municípios brasileiros (BRASIL, 2010) crianças que nasceram em HAC tiveram a duração média de 60,2 dias de
AME enquanto que crianças que não nasceram em HAC apresentaram um AME médio de 48,1 dias.

É notória a influência das orientações e apoio neste cenário, onde a mãe tem o seu primeiro encontro com a amamentação, sendo necessário que os profissionais estejam preparados para orientarem e estimularem esta prática no ambiente hospitalar.

$\mathrm{O}$ terceiro cenário de atenção à mulher e à criança são as consultas pós-natal, ou puericultura. Neste momento de encontro com o binômio é que podemos conhecer a realidade a que este se encontra exposto, cultura e valores que apresentam influencia na maneira de pensar a alimentação deste bebê, as dificuldades enfrentadas nesta aproximação, o novo olhar com o qual a mãe percebe a amamentação.

As falas das mães nos garantem que a orientação tem sido realizada neste momento, porém muitas delas referiram orientações desatualizadas, sendo que muitas foram seguidas, como é expresso a seguir:

Falavam assim: "oh mãe, você dá mama certinho para ela, na hora certa... de duas em duas horas" (E6).

A amamentação deve ser em livre demanda, ou seja, oferecida no momento em que a criança sente a necessidade de se alimentar, sem restrições de horários. É preciso deixar claro que nos primeiros meses a criança mame em horários e freqüências irregulares, para que não seja confundida com demanda insuficiente ou "leite fraco" (BRASIL, 2009a).

No Manual do Ministério da Saúde (BRASIL, 2009a) é orientado que não se realizem manobras para fortalecimento dos mamilos, como uso de buchas e toalhas que podem ser prejudiciais à integridade da pele. Encontraram-se relatos sobre essa orientação em nossas entrevistas, demonstrando uma desatualização dos profissionais de saúde responsáveis por transmitir as orientações:

[...] que eu tinha que tomar sol, ai esfoliar com aquela buchinha vegetal [...] (E7).

É necessário que o profissional de saúde esteja 
preparado para orientar o aleitamento materno de forma correta. Para isso deve-se desenvolver a competência profissional por meio de educação continuada, para que aja a otimização das orientações no que diz respeito ao aleitamento, sempre se atualizando em relação ao que é proposto por estudos realizados nesta esfera e modificado em protocolos (BRASIL, 2009b).

Nos relatos seguintes encontraram-se orientações quanto o aumento da produção de leite e os benefícios trazidos pela amamentação, orientações essenciais para promover esta ação:

A enfermeira às vezes na pós consulta, uma ou duas vezes que a auxiliar, veio para perguntar, e falou da importância... 'Está dando mamá mãe? ' [...] Falou da alimentação... 'você toma bastante sopa, toma bastante liquido, para que não fique sem o leite' Ela me deu uma orientação assim... até a pediatra também falou 'tomar bastante liquido' (E1).

Quando eu tava amamentando que eu passasse o próprio leite no bico do peito e isso ajudou bastante. [...] Toda vez que eu levava, ele estimulava bastante para dar o peito e sempre falava bastante que era muito importante a amamentação (E8).

Não foi mencionada pelas mães a orientação sobre o fato de a criança não ter o desejo de ingerir determinados alimentos, apesar de esta afirmação ter aparecido no tema: "A influencia da família no processo de aleitamento materno exclusivo". Esta orientação deveria estar presente no momento da puericultura, onde a criança apresenta seu crescimento e desenvolvimento, e sabido que este é um mito presente em muitas famílias como forte fator na interrupção do AME.

Um fator bastante presente nas falas das mães entrevistadas foi o conhecimento prévio sobre o assunto e a experiência com aleitamento de outros filhos:

Eu também já fiz o curso de auxiliar de enfermagem, já sabia bastante coisa sobre isso (E1).

Como eu já tive dois, eu já havia amamentado, os três eu amamentei, então eu tive mais facilidade (E3).

Da outra já foi mais fácil, eu já estava acostumada [...] da primeira foi mais difícil (E5).

Ninguém falou para mim, eu já sabia. Desde o meu primeiro filho (E6).
Nós trabalhavamos com a pastoral da criança, ensinando as mães a dar de mama (E11).

Muitas pesquisas trazem a experiência materna como determinante na duração da amamentação. Um estudo realizado nas capitais brasileiras e distrito federal apontaram a variável "primeiro filho" como fator de risco para a introdução de outros líquidos (sucos, chás, mingaus) nos primeiros seis meses de vida (SALDIVA et al., 2011).

Apesar de muitas referências às orientações no período de puericultura, pode-se observar que as informações recebidas foram, muitas vezes, equivocadas. Sabemos que estas orientações podem trazer dificuldades maiores no processo de aleitamento e até mesmo determinar o desmame precoce.

Notou-se que o aleitamento materno tem sido abordado nos diversos cenários de atenção, mesmo que em menor intensidade em algum deles. Porém é preciso nos atentar à qualidade das informações e ao momento em que estão sendo orientadas. Olhar e entender a evolução gestação - parto - puerpério é imprescindível para que possamos intervir no momento certo, conhecendo as necessidades intrínsecas a cada etapa, de acordo com aquilo que é vivenciado pela mulher, adequando e atualizando as orientações a cada uma delas.

Apreendeu-se nas falas que os serviços criam importantes condições de vulnerabilidade em relação às informações dadas às gestantes, em virtude de profissionais desatualizados, o que pode ser atribuído à falta de um programa de capacitação permanente, reciclagens, ou ainda, o estímulo das instituições para que os profissionais frequentem cursos, congressos, fóruns, que possibilitem a atualização de conhecimentos técnicos e científicos, para uma atenção atualizada e bem fundamentada.

\section{O Apoio dos Profissionais de Saúde}

Pôde-se analisar na fala das mães a importância de estabelecer-se uma comunicação com o profissional de saúde e o reconhecimento desta comunicação 
como forma de apoio, bem como a falta dela em momentos que se fazia necessário:

Foi importante, porque eu não tinha assim muita certeza se eu ia amamentar. [...]. Então eu ia ao médico a gente ficava conversando e ele foi abrindo minha mente, minha cabeça (E1)

[...] Mas assim apoio mesmo, de falar assim 'alguém me auxiliou, alguém me explicou', não tive (E2)

Mais nada de... chegar, explicar e conversar não... (E5)

Mas toda vez que eu chegava lá eles conversavam bastante com a gente, as enfermeiras... deram bastante apoio, me ajudaram, sempre conversavam (E8).

O aconselhamento em saúde deve se pautar na escuta dos sentimentos e das experiências que essas mães têm vivido, que é particular a cada uma. A partir dessa escuta levá-la a decidir o que será melhor para ela, fazendo-a adquirir autoconfiança, não 'despejando' conhecimentos e impondo a maneira como devem realizar o cuidado ao seu filho (TACLA, 2006).

Diante de uma situação nova na vida de muitas mulheres que se descobrem gestantes, nasce a necessidade de responder a duvidas que surgem a respeito do período em que se encontram. O aleitamento muitas vezes é experiência de sofrimento e aprendizado, que exige conhecimento das técnicas e dos benefícios proporcionados por ele, para que se garanta a amamentação exclusiva.

O dicionário da língua portuguesa trás como significado de apoio: tudo o que serve de sustentáculo ou suporte; auxílio; socorro; aprovação; aplauso. Apoiar a mãe que amamenta é dar suporte e auxiliá-la nos momentos de dificuldades, decidir juntamente com ela o que será melhor para o binômio em relação à nutrição do bebê, por meio de comunicação, paciência e respeito aos seus conceitos e conhecimentos, aprovando suas escolhas, independentemente de quais forem.

Estar atentos a comunicação não verbal e as dificuldades apresentadas é fundamental para uma intervenção adequada, como se percebe no relato a seguir:
Sempre quando eu precisei [...] Ai elas vieram, a enfermeira, um dia que eu estava chorando, eu estava chorando porque o leite não descia e ela chorava de fome. Ai ela falou: 'não mãe, vai descer sim, você tem leite, olha essa aguinha branca é o colostro’ (E11).

Muitas mães podem ter receio em exprimir suas dúvidas, medos, dificuldades durante a amamentação. É preciso dedicar tempo para um diálogo aberto, longe de julgamento, deixando espaço para que ela fale e coloque seus sentimentos em relação a este novo que está acontecendo, muitas vezes, de uma maneira difícil em suas vidas (TACLA, 2006).

Deve-se atentar ao fato de que muitas mães vivenciam intervenções profissionais que não trazem apoio, sendo comunicações não terapêuticas, informações erradas, omissão de orientações, e estas não percebem tais situações, como são expressas nas falas a seguir:

Eu lembro que no hospital elas falavam que é assim mesmo, que doía (E3).

Ela achava mais fácil tomar o NAN na mamadeira. A doutora que receitou pra ela (E5).

[...] que era assim mesmo, até com relação a ter ferido um pouco, que era normal, que eu tinha que tomar sol, ai esfoliar com aquela buchinha vegetal (E7).

Ai eles falaram 'passa um remedinho, ai vai indo, pois você tem que amamentar fia, tem que amamentar, você é mãe agora, agora tem que agüentar as dores.

Você não passou a dor mais forte?' (E9)

É importante reforçar aqui a influência que a opinião, comportamento e orientações do profissional de saúde exercem sobre a opinião que está sendo formada pelo indivíduo que as recebe, e a maneira como estas podem agir na decisão pelo desmame precoce ou pelo não aleitamento. Afirmar que a dor na amamentação é normal e que o aleitamento é garantia de uma maternidade onde existe amor e onde se cumpre a obrigação maternal é sinal de despreparo profissional. Profissional este que não tem subsídios suficientes para intervir adequadamente para prevenir e tratar as fissuras mamilares, apelando para a resignação da mãe enquanto que esta deveria estar recebendo 
do profissional uma ajuda competente para o problema da pega incorreta e fissura. Isto é criar vulnerabilidade programática.

$\mathrm{Na}$ fala a seguir percebe-se como a opinião do profissional interfere no delineamento do conceito de amamentação e na percepção da mãe sobre esse processo:

Mas até a pediatra dele um dia me disse que talvez eu não devesse ter amamentado mais de seis meses. [...]. Ela me disse "é na verdade eu acho que deveria amamentar até o sexto mês só'. [...] Eu acabei me arrependendo de ter dado tanto tempo, porque daí bagunça tudo as coisas... eu até aconselhava as pessoas a não amamentarem por tanto tempo, só até o sexto mês mesmo (E1).

É evidenciada em diversos estudos a necessidade que a mãe apresenta de ter o apoio do profissional de saúde, como na avaliação profissional periódica realizada na puericultura, como fonte de informações para si, avaliação de cuidado para com a criança e acompanhamento do seu desenvolvimento e crescimento.

No momento em que este profissional posicionase com opiniões contrárias ao que é estipulado nos conceitos de amamentação está estabelecendo uma vulnerabilidade bastante forte para o não aleitamento. Pode-se também relacionar a escolha por este tipo de orientação ao despreparo profissional, que não se dispõe a ouvir e discutir possibilidades de se mudar a situação de dificuldade a qual a mãe esta submetida.

O profissional de saúde tem a responsabilidade de olhar para as fragilidades que o aleitamento tem causado ou sofrido e propor, juntamente com a mãe e família, alternativas que solucionem tais fragilidades e permita uma continuidade no processo de amamentação.

Com a realização das entrevistas descobriu-se ainda uma fragilidade no que se refere ao apoio prestado durante o pré-natal, sendo citado por muitas mães como insuficiente, ou ainda, inexistente:

Não, não, Para ser bem sincera eu não lembro, não lembro (E3).
No pré-natal não foi falado muito nisso. Só o fato de ser a única alimentação necessária (E5)

Não é igual a posto, lá no [...] te dá mais atenção (E10)

Durante a assistência pré-natal, as mulheres devem ser informadas sobre os benefícios da amamentação e as desvantagens do uso de leites não humanos e devem ser orientadas quanto às técnicas da amamentação para aumentar a sua habilidade e confiança (BRASIL, 2009a).

Esta pesquisa mostra que as orientações e apoio têm sido realizados de maneira bastante eficaz no ambiente hospitalar, sendo reconhecido como: ajuda, paciência e persistência:

No hospital, que as auxiliares me ajudaram bastante, com muita paciência (E1)

Ela teve muita dificuldade, as enfermeiras eram muito persistentes (E3)

Além dos relatos sobre o bom apoio neste ambiente as mães apontaram o aleitamento materno na primeira hora de vida como ponto positivo para a amamentação, onde é estabelecido vínculo, também pelo contato pele a pele:

\footnotetext{
Mas no hospital eu lembro que a primeira coisa que eles fazem, o primeiro contato do bebe com a mãe é colocar no peito (E3).
}

Assim que ela nasceu já colocaram para ela mamar, achei muito importante (E8).

Eu gosto assim na [...]: acabou de nascer, já coloca pra mamar. Ai eu falei "nossa é uma delicia", porque dai a criança já se sente mais protegida. Eu acho bom.

Gosto muito dessa parte (E11).

Esta conduta faz parte do que a OMS estipulou como "Os 10 passos para o sucesso do aleitamento materno", que é adotado pelos HAC para a promoção da amamentação. O guia de atenção à saúde do recém nascido, elaborado pelo MS, preconiza que após o parto de bebês saudáveis deve-se estimular o contato pele a pele e o aleitamento materno na primeira hora de vida, evitando-se intervenções desnecessárias em sala de parto, que acabam se tornando rotineiras (BRASIL, 2011).

Observou-se que dentro das intervenções prestadas no período pós-natal a vista domiciliar e a 
aproximação do profissional de saúde expressa um valor importante na visão das mães:

Eles vinham na minha casa... As meninas do postinho ali vinham em casa... Orientavam, vinham para fazer orientação [...]... Sempre elas estavam aqui... (E6).

Foi bom, porque as enfermeiras desciam lá onde eu morava [...] E eles sempre passavam em casa para saber como que ela estava (E11).

E quando eu ganhei ele não tinha ninguém que ia em casa não (E12).

Os primeiros dias de vida devem ser assistidos de perto, pois é o momento em que toda a família adapta-se a uma nova rotina em torno de um novo habitante em sua casa. Isso não é diferente para o aleitamento materno. Os primeiros dias em que a mãe encontra-se sem a presença dos profissionais de saúde, como na maternidade, são decisivos para o estabelecimento da amamentação bem como sua continuidade. Nesse momento é importante que se ressalte as propriedades dessa alimentação exclusiva, técnicas corretas de amamentação, fazendo uma abordagem que também inclua a família.

Apesar das falhas que ainda ocorrem nos serviços de saúde, não se pode deixar de notar o crescimento do apoio recebido em relação aos anos anteriores, sendo reconhecido também pelas mães que já tinham a experiência com outros filhos:

Foi essa ajuda pra mim foi muito importante, muito bom. Que eu tenho outro filho e na época eu não tive essa ajuda e eu sofri bastante [...] Naquela época não tinha esse apoio assim... essa preocupação toda (E8).

A perspectiva de amamentar vem sofrendo grandes mudanças, onde se tem criado novos conceitos e sido reconhecida a sua importância. É preciso criar a consciência individual de cada profissional, entendendo-se a intervenção e apoio na amamentação como particular a cada mulher. O cuidado com esta não deve ser realizado em massa, como se todas fossem passar pelas mesmas dificuldades. Conhecer a história, o contexto ao qual pertence cada família que chega ao seu serviço é essencial para uma intervenção adequada, que vise tanto o aleitamento materno exclusivo, como um cuidado diferenciado a cada uma delas, atuando com equidade e integralidade.

O serviço de saúde, frente ao insucesso de um processo de aleitamento, tem a grande tentação de atribuir esta situação à vontade da mãe. Toda situação que traga vulnerabilidade ao não aleitamento deve ser avaliada e modificada. É a isso que o profissional de saúde deve estar atento, preparado a, empaticamente, "fundir horizontes", tentando que o outro consiga ver como eu vejo e que eu veja como ele vê, e deste modo chegar juntos a uma decisão adequada sobre como estabelecer um cuidado ideal no que se refere ao aleitamento de cada criança.

\section{Considerações Finais}

Concluiu-se na presente pesquisa que as mães sentem necessidade de serem apoiadas desde o prénatal até o puerpério, tanto pela família como pelos profissionais nos serviços de saúde, tendo como foco as dificuldades vivenciadas no decorrer do processo de amamentação.

O ser humano, no âmbito da saúde, deve ser visto como aquilo que é pelas influencias culturais, sociais e isso deve ser considerado no processo de cuidar das mulheres e suas famílias para que não se crie ou, pelo menos, para diminuir a vulnerabilidade ao não aleitamento. Não se pode esquecer que este ser humano é formado por uma história e fatores que o fazem vulneráveis em suas escolhas e nosso papel consiste em, cientes disso, traçar estratégias efetivas para o alcance de nossos objetivos de saúde para aquela família. Seus valores e história de vida precisam ser respeitados e incluídos na assistência, para que possamos atingir melhores resultados no sentido de aumentar as taxas de aleitamento materno exclusivo no município. 


\section{Referências}

AYRES, J.R.C.M.; PAIVA, V.; FRANCA JR, I. From natural history of disease to vulnerability: changing concepts and practices in contemporary public health. In: PARKER, R.; SOMMER, M. (Ed.). The routledge handbook of global public health. New York: Routledge; 2011. p. 98-107.

BARDIN, L. Análise de conteúdo. Lisboa: Ed. 70, 2008.

BRASIL. Ministério da Saúde. Departamento de Ações Programáticas Estratégicas. Rede amamenta Brasil: caderno do tutor. Brasília, 2009b.

BRASIL. Ministério da Saúde. Departamento de ações programáticas e estratégicas. Pesquisa de prevalência de aleitamento materno em municípios brasileiros. Brasília, 2010.

BRASIL. Ministério da Saúde. Departamento de ações programáticas e estratégicas. Atenção à saúde do recém-nascido: guia para os profissionais de saúde. Brasília, 2011.

BRASIL. Ministério da Saúde. Saúde da criança: nutrição infantil: aleitamento materno e alimentação complementar. Brasilia, 2009a.

INSTITUTO DE PESQUISA ECONÔMICA APLICADA - IPEA. Objetivos de desenvolvimento do milênio. Relatório nacional de acompanhamento. Brasília, 2004.

LONDRINA. Secretaria Municipal de Saúde. Plano Municipal de Saúde - 2010-2013. Londrina, 2010. Disponível em: <http://www1.londrina. pr.gov.br/dados/images/stories/Storage/sec_saude/ Plano\%20Municial/plano_municipal_2010_2013. pdf $>$. Acesso em: 21 ago. 2012.

LOPES, W. O.; SAUPE, R.; MASSAROLI, A. Visita domiciliar: tecnologia para o cuidado, o ensino e ao pesquisa. Ciência, cuidado e saúde, Maringá, v. 7, n. 2, p. 241-247, abr./jun. 2008.

MARQUES, E. S.; COTTA, R. M.; MAGALHÃES, K. A.; SANT'ANA, L. F.; GOMES, A. P.; SIQUEIRA-BATISTA, R. A influência da rede social da nutriz no aleitamento materno: o papel estratégico dos familiares e dos profissionais de saúde. Ciência \& Saúde Coletiva, Rio de Janeiro, v. 15, supl.1, p. 1391-1400, 2010.

MEYER, D. E.; MELLO, D. F.; VALADÃO, M. M.; AYRES, J. R. Você aprende. A gente ensina? Interrogando relações entre educação e saúde desde a perspectiva da vulnerabilidade. Cadernos de Saúde Pública, Rio de Janeiro, v. 22, n. 6, p. 13351342, 2006.

MONTEIRO, J. C. S.; GOMES, F. A.; NAKANO, A. M. S. Amamentação e o seio feminino: uma análise sob a ótica da sexualidade e dos direitos reprodutivos. Revista Texto e Contexto Enfermagem, Florianópolis, v. 15, n. 1, p. 146-50, fev. 2006.

MÜLLER, F. S.; SILVA, I. As representações sociais de um grupo de mulheres/ nutrizes sobre o apoio à amamentação. Revista Latino Americana de Enfermagem, Ribeirão Preto, v. 17, n. 5, set./out. 2009.

NAKANO, A. M. S. As vivências da amamentação para um grupo de mulheres: nos limites de ser "o corpo para o filho" e de ser "o corpo para si”. Caderno de Saúde Pública, Rio de Janeiro, v. 19, p. 355-363, 2003.

SALDIVA, S. R.; VENANCIO, S. I.; GOUVEIA, A. G.; CASTRO, A. L.; ESCUDER, M. M.; GIUGLIANI, E. R. Influência regional no consumo precoce de alimentos diferentes do leite materno em menores de seis meses residentes nas capitais brasileiras e Distrito Federal. Caderno de Saúde Pública, Rio de Janeiro, v. 27, p. 2253-2262, 2011.

SILVA, A. A. M. Amamentação: fardo ou desejo? Estudo histórico-social dos saberes e práticas sobre o aleitamento materno na sociedade brasileira. 1990. Tese. (Mestrado em Medicina) - Faculdade de Medicina de Ribeirão Preto - USP, Ribeirão Preto.

SOUZA, S. A. D. H.; MIGOTO, M. T.; ROSSETtO, E. G.; MELLO, D. F. Prevalência 
do aleitamento materno e fatores associados no município de Londrina-PR. Acta Paulista de Enfermagem, São Paulo, v. 25, n. 1, p. 29-35, 2012.

SOUZA, S. N. D. H. O aleitamento materno na perspectiva da vulnerabilidade programática. 2010. Tese (Doutorado em Ciências) - Escola de Enfermagem de Ribeirão Preto, Universidade de São Paulo, Ribeirão Preto. 2010.

SUSIN, L. R. O.; GIUGLIANI, E. R. J. Inclusion of fathers in an intervention to promote breastfeeding: impact on breastfeeding rates. Journal of Human Lactation, Rio Grande, v.24, n. 4, 2008.

TACLA, Mauren T. G. M. Ouvir, entender, orientar. In: CASTRO, L. M. C. P.; ARAUJO, L. D. S. (Org.). Aleitamento materno: manual prático. Londrina: AMS, 2006. p. 51-54.

TEIXEIRA, M. A.; NITSCHKE, R. G. Modelo de cuidar em enfermagem junto às mulheres - avós e sua família no cotidiano do processo de amamentação. Revista Texto e Contexto Enfermagem, Florianópolis, v. 17, n. 1, p. 183-191, jan./mar. 2008.

WORLD HEALTH ORGANIZATION - WHO. 10 facts on breastfeeding. July 2012. Disponível em: $\quad<$ http://www.who.int/features/factfiles/ breastfeeding/en/>. Acesso em: 17 out. 2012. 
